\title{
Clause-final particles and focus in Eastern Cham
}

\author{
Kenneth Baclawski Jr.*
}

\begin{abstract}
We demonstrate that clause-final particles in Eastern Cham (Austronesian: Vietnam) are right-branching syntactic heads that trigger predicate raising. This provides support for Simpson (2001)'s analysis of a clause-final modal found in Vietnamese, Thai, and other Southeast Asian languages, and militates against a mixed-headed analysis (pace Kayne 1994). Evidence for predicate raising comes from a novel diagnostic: the interaction between focus-driven object shift and multiple clause-final particles in one clause. Finally, we propose that clause-final particles are VP-level focus phrases, which divide a sentence into a focus and presupposition (cf. Rizzi 1997) and incidentally contribute modal or aspectual semantics.
\end{abstract}

Keywords. syntax, focus, modality, object shift, Southeast Asia, Austronesian

1. Introduction. Eastern Cham (Austronesian: Vietnam), like many Southeast Asian languages, has a set of clause-final particles that typically mark mood or aspect, such as $h u$ 'ROOT MODAL'. In unmarked contexts, these particles follow the verb and its arguments (1a), though they may be followed by discourse-level particles, like the polar question marker hlej. However, focussed material in the predicate can be extraposed to the right of these particles (1b).

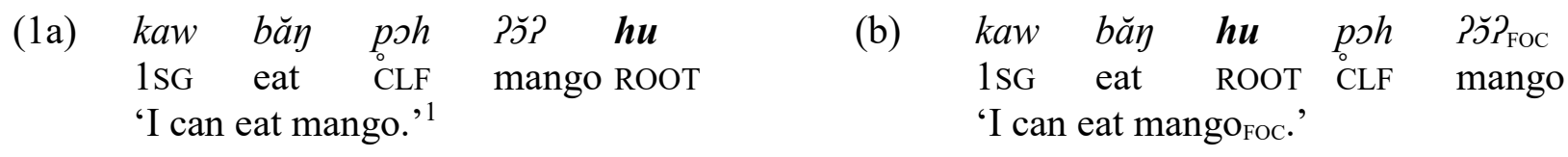

Simpson (2001) analyses this phenomenon in a variety of Southeast Asian languages. Notably, numerous languages in the region have a clause-final modal likely related through borrowing or calquing (e.g. Thai dai, Vietnamese đuợc, Cantonese dak; cf. Enfield 2005). A natural surface analysis of $(1 \mathrm{a}-\mathrm{b})$ would involve a mixed-headed approach (2a): whichever phrase is headed by $h u$ is head-final (cf. Erlewine 2017 on Mandarin). However, these languages are all SVO and generally right-branching, which would make this phrase a conspicuous left-branching outlier. Simpson proposes instead an analysis that preserves a right-branching structure by incoporating obligatory predicate raising $(2 \mathrm{~b})$. The mixed-headed approach is more economical, involving fewer intermediate phrases. However, the predicate-raising approach keeps in line with the

\footnotetext{
${ }^{*}$ My sincere thanks to the Cham communities of Phan Rang province and Ho Chi Minh City, Vietnam, especially to Sakaya and Sikhara for their help with my research. Thanks also to Peter Jenks, Line Mikkelsen, Elise Stickles, Nico Baier, and Carrie Spadine for their help with the data. Any mistakes are my own. This material is based upon work supported by the National Science Foundation Graduate Research Fellowship under Grant No. DGE-1106400. Any opinion, findings, and conclusions or recommendations expressed in this material are those of the author(s) and do not necessarily reflect the views of the National Science Foundation. Author: Kenneth Baclawski Jr., University of California, Berkeley (kbaclawski@berkeley.edu).

${ }^{1}$ Orthography is largely IPA, with some exceptions in line with the Cham linguistic tradition (e.g. Moussay 2006): open circles underneath consonants indicate falling, breathy tone on the following vowel; superscript consonants indicate coarticulation or highly reduced sesquisyllables. Note that there is significant inter-speaker phonetic and lexical variation even within small villages (Baclawski 2016) underlying this data. Clause-final particles are generally bolded for emphasis. Abbreviations used: $\mathrm{CLF}=$ numeral classifier; $\mathrm{EMPH}=$ emphatic particle; $\mathrm{FOC}=$ focus; ITER = iterative aspect; $\mathrm{QP}=$ polar question particle; $\mathrm{PROG}=$ progressive aspect; $\mathrm{ROOT}=$ root modal; $\mathrm{SG}=$ singular; $(\mathrm{VN})=$ loanword from Vietnamese. Data is from the author's fieldwork in Ho Chi Minh City, Vietnam with seven native speakers in 2016.
} 
broader typology of these languages (cf. also Simpson 2005 on similar work explaining mixedheadedness in Southeast Asian DP's).

(2a) Mixed-headed derivation of (1a)

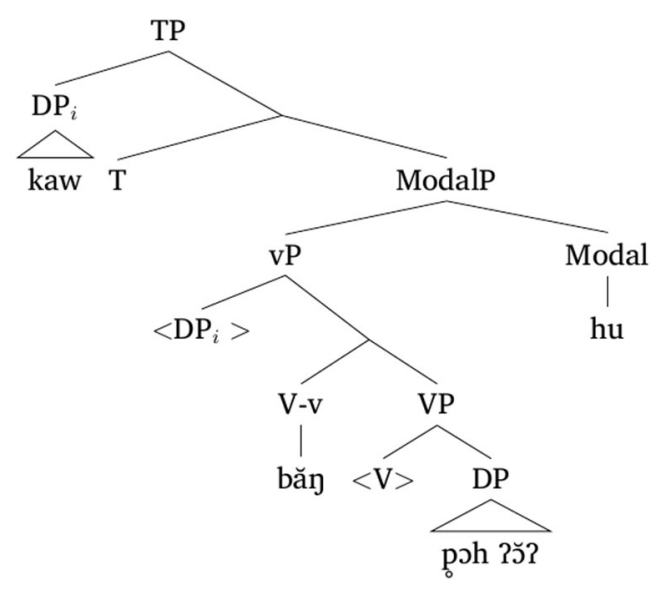

(2b) Predicate-raising derivation for (1a)

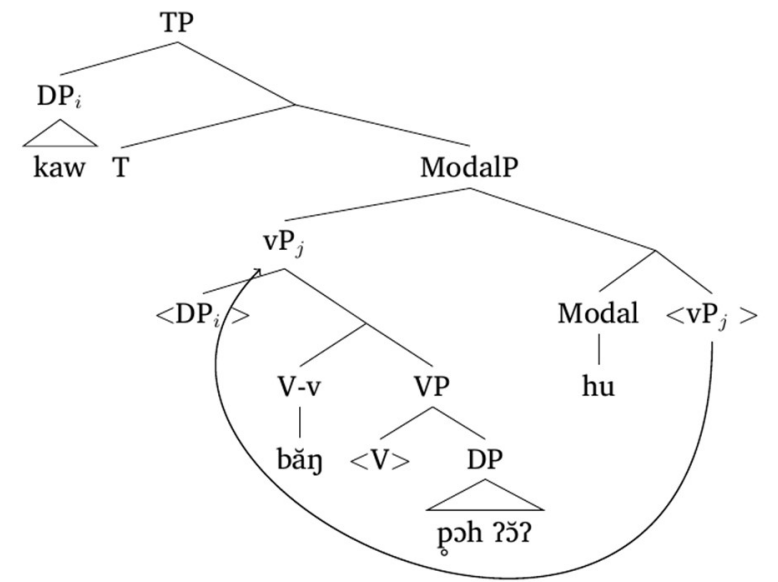

We propose that Eastern Cham clause-final particles must involve a right-branching, predicateraising structure, given evidence from the cooccurrence of multiple particles in one sentence. Eastern Cham has a set of particles which behave like $h u(3 \mathrm{a}-\mathrm{b})$.

(3a) Clause-medial: $c \breve{c} \overrightarrow{2}$ ' 'near prospective', to? 'progressive', $k a$ 'incompletive'

(3b) Clause-final particles: $o$ 'negative', $h u$ 'root modal', v̌̆t? 'iterative', mı̆n 'emphatic', $(p l s h) c i$ 'completive'

In Section 2, we will show that the clause-final particles have rigid relative scope in the clausal spine. Evidence primarily comes from answers to polar questions, through the Predicator Test (Visonyanggoon 2000). In Section 3, it will be shown that focussed material in the predicate can be extraposed to the right of these clause-final particles. Then, in Section 4, the interaction between focus shift and multiple cooccurring clause-final particles will lend strong evidence that there must be predicate-raising in Eastern Cham.

2. Clause-final particles in the clausal spine. In this section, we will establish that Eastern Cham clause-final particles are syntactic heads with rigid relative syntactic scope. First, it is worth noting that these particles like $h u$ are not verbal affixes. Words can intervene between the verb and $h u$ (e.g. the object in 1a). These intervening words do not show obvious characteristics of noun incorporation, as they can be definites, whole phrases, and/or adjuncts and adverbials. Furthermore, Eastern Cham generally lacks bound morphology, along the same lines as Vietnamese.

The major evidence for this section, however, comes from answers to polar questions, via the 'predicator test'. The predicator test applies in languages where polar questions can be answered by a single verb or auxiliary. According to the test, only the structurally highest verb or auxiliary may be a felicitous answer. For example, in Thai, the main verb is a felicitous answer in the absence of auxiliaries (4b). But auxiliaries (5b), including clause-final auxiliaries (6b) outscope the main verb. 
(4a) Thai (Visonyanggoon 2000: 117-118, 141)

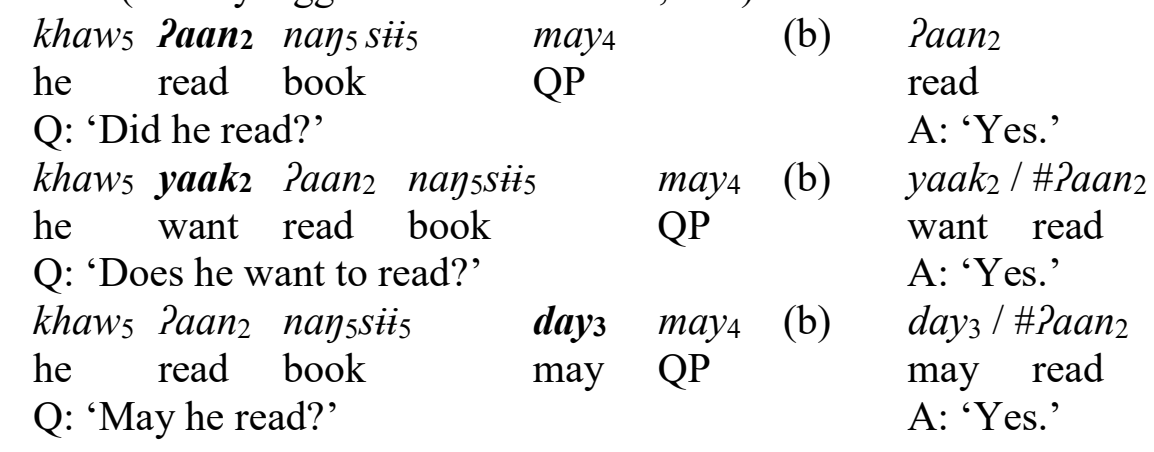

The standard analysis of this phenomenon is that polar questions in these languages involve a polarity phrase head with a feature that selects for a verbal head (assuming a feature that targets both verbs and auxiliaries). Martins (1994) formalizes this as a $\Sigma$ P, which dominates vP and whose head probes for the most local head with verbal features (citing López 1999).

This phenomenon is widespread in Southeast Asia. It is attested in Vietnamese (Austroasiatic), which is a language that has been in intense contact with Eastern Cham for centuries. Thompson (1987) describes "predicative fragments": modals and aspect markers that may answer polar questions (e.g. được 'root modal', rồi 'perfective'). It is also attested in Indonesian (Austronesian), a language closely related to Eastern Cham. Sneddon, et al (2012: 324) list possible responses to polar questions, which are all modals or aspect markers (e.g. boleh 'may', sudah 'already'). We thus have every reason to suspect that the predicator test should apply in Eastern Cham, and that modal auxiliaries should be pertinent verbal heads.

Indeed, the predicator test does apply in Eastern Cham. In particular, consider the examples in (7-10) with $h u$ 'root modal' and $\nu \grave{t}$ ? 'iterative'. The main verb is a felicitous answer in the absence of auxliaries or serial verbs (7b). The iterative $\overrightarrow{v t}$ ? is a felicitous answer in $(8 b)$ as the highest auxiliary. However, the modal $h u$ and the progressive to? are the only felicious answers in $(9 \mathrm{~b}, 10 \mathrm{~b})$, as they outscope $v \breve{t}$ ? and the main verb.

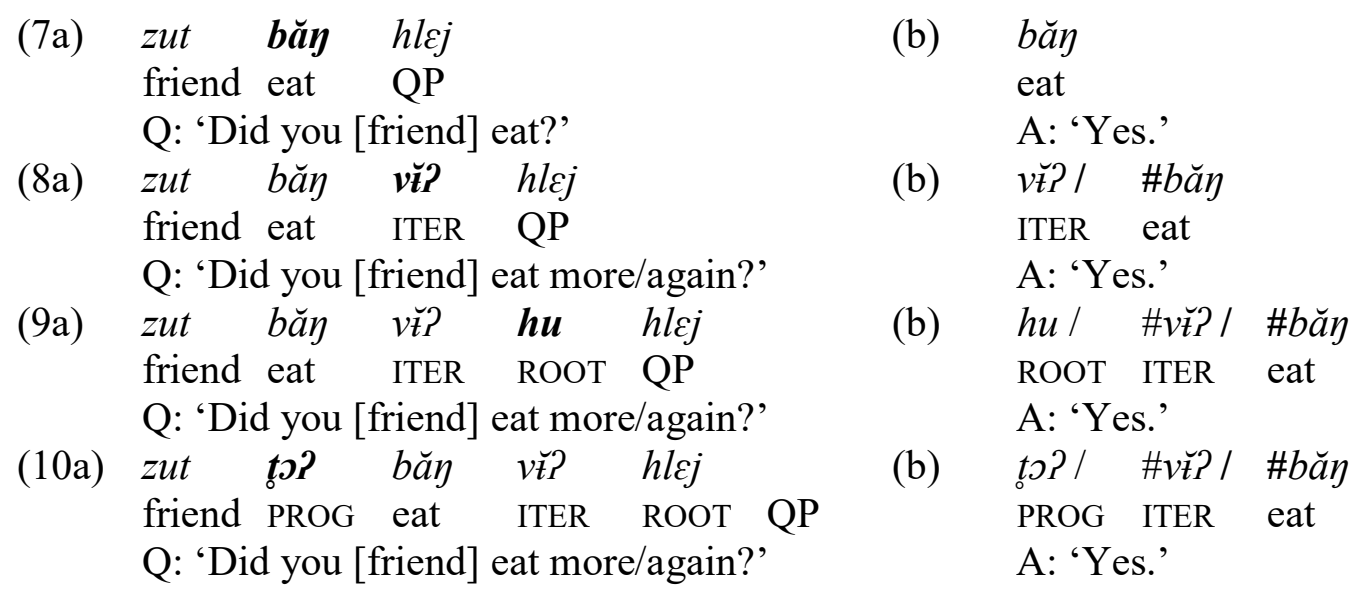

We conclude that $v \breve{t} ?, h u$, and to? are all syntactic heads with a verbal feature. Furthermore, we can assert the relative scope: $h u$ 'root modal', to? 'progressive' $>>v \breve{t r}$ ' 'iterative' $>>$ main verb. Note that the root modal and progressive cannot cooccur, so their relative scope is unclear.

A secondary test to confirm this conclusion is fragment answers. In Eastern Cham, polar questions may also be answered by varying degrees of fragments, which we take to be a proxy 
for constituency. The felicitous responses in $(11 \mathrm{~b}, 12 \mathrm{~b})$ are all constituents according to the scope above. In other words, $v \breve{t}$ ? 'iterative' is clearly lower in the clausal spine than $h u$ 'root modal' and to? 'progressive'.

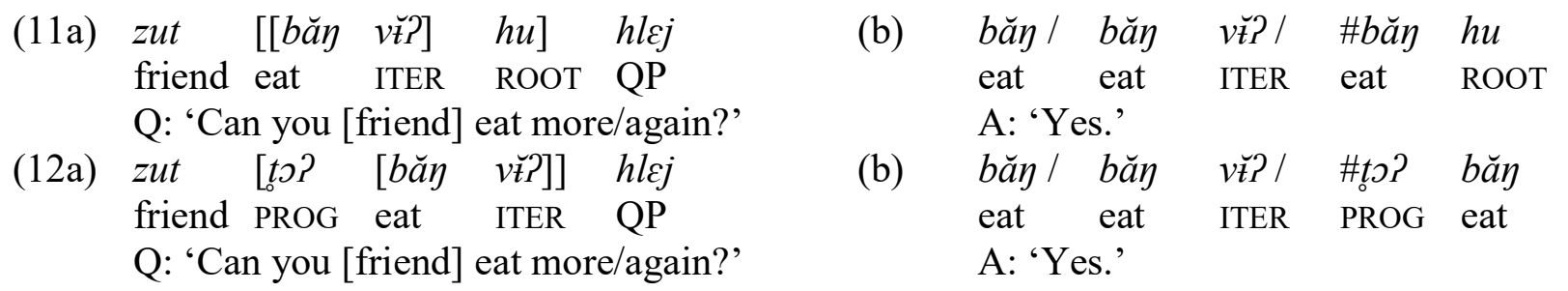

In the vein of Simpson (2001), there are two obvious approaches to this data: a mixed-headed approach, where the clause-final particles are left-branching (13a), or a predicate-raising analysis (13b). To account for the relative order in (13b), we must posit a 'rolling-up' movement: first, the vP undergoes predicate raising to the specifier of the AspectP. Then, the whole AspectP undergoes raising to the specifier of the ModalP. (For Simpson, this movement targets unspecified intermediate YP's.) While this roll-up movement may seem less preferable at first, the interaction between focus movement and multiple clause-final particles will militate in favor of this analysis. ${ }^{2}$

\section{Mixed-headed derivation of two clause-final particles}

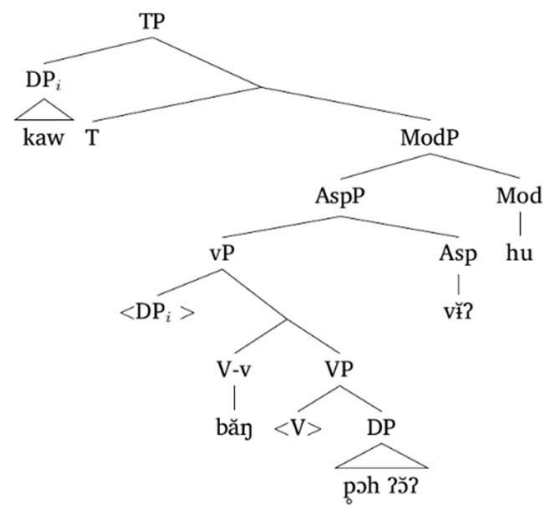

(b) Predicate-raising derivation for two clause-final particles

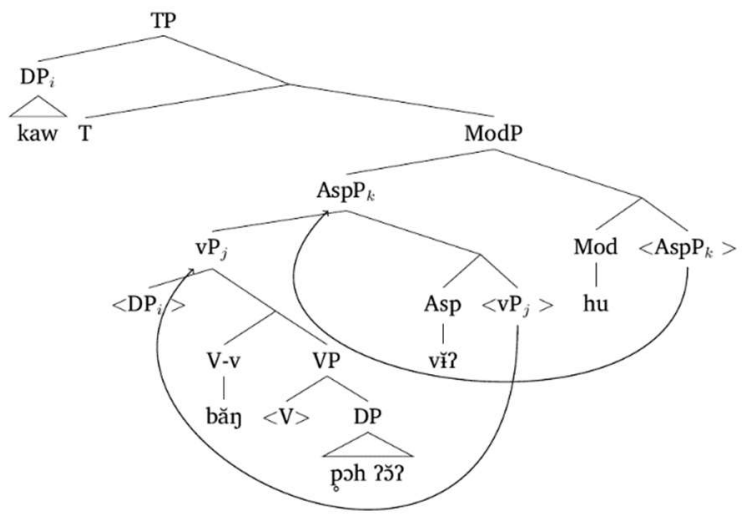

3. Object shift and focus movement. In Eastern Cham, like some other languages of Southeast Asia, objects may sometimes be extraposed to the right of clause-final particles. Simpson (2001) reports that this occurs in Vietnamese, Middle Chinese, and Thai, and attributes object shift to focus. Object shift is also clearly related to focus in Eastern Cham: it is infelicitous for object shift to occur when the subject is focussed (14a), but it is preferred if the object is under focus $(15 a){ }^{3}$

\footnotetext{
${ }^{2}$ Cf. Simpson (2001: 95-98) for arguments against a "sentential subject" analysis, in which clause-final modals head TP/IP, while the rest of the sentence is embedded in subject position. The data in Section 4 on multiple clause-final particles constitutes even more evidence against such an analysis, as it would seem to predict only one clause-final particle per clause.

${ }^{3}$ Grammaticality judgments are presented as recorded in the data. \# refers to infelicity, ? refers to a "better than" judgment: the speaker was presented with two sentences and is asked if one is better or they are equally felicitous. Some speakers consistently gave stronger judgments than others, but the paradigms reported here appear to be robust.
} 
(14) ConTeXt: Who can eat mango?

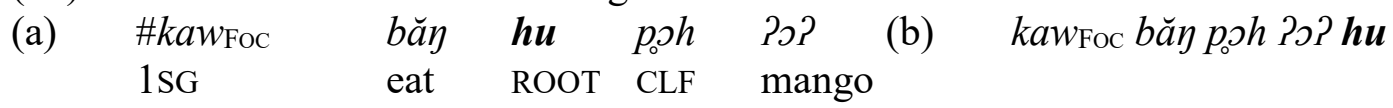

A: 'IFoc can eat mango.'

(15) CONTEXT: In the morning, what can you eat?
(a) kaw băy hu poh ?o? Foc
$1 \mathrm{SG}$ eat ROOT CLF mango
(b) ?kaw băy poh ?o? Foc hu

A: 'In the morning, I can eat mangofoc.'

Syntactic weight does not seem to determine object shift. In an out-of-the-blue context, objects with relative clauses (17a) or adjectives/numerals (17b) do not prefer to be shifted. Note that these sentences are felicitous if $v \breve{t} ?$ 'iterative' is clause-final. Syntactic weight may be a factor on some level, but it seems to be focus that primarily determines object shift.

(17) CONTEXT: Out of the blue.

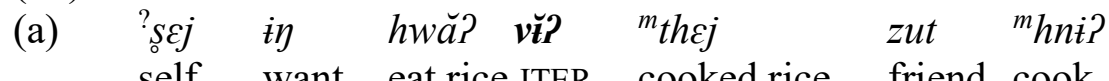

self want eat.rice ITER cooked.rice friend cook

'I want to eat the rice you [friend] cooked.'

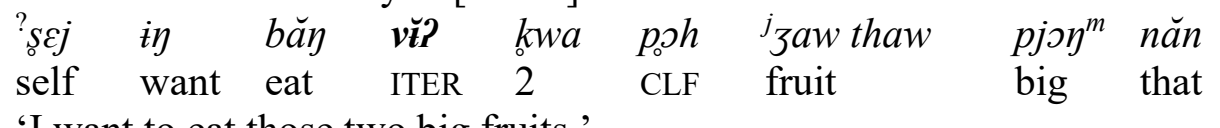

'I want to eat those two big fruits.'

Next, while focus movement is claimed only to mark identificational/exhaustive focus (cf.

Horváth 2010), this object shift does not seem to do so. A crucial test is association with 'only', which is a canonical identificational focus marker (É. Kiss 1998). In Eastern Cham, object shift is often accompanied by št ... min 'only' (18a). However, it is easy to construct examples where 'only' occurs, but object shift is infelicitous (19a). Additionally, object shift is not felicitous with second-occurrence focus.

(18) CONTEXT: In the morning, what can you eat?

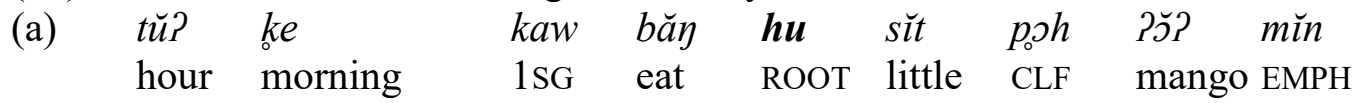

A: 'In the morning, I can only eat mango.'

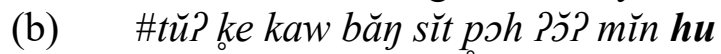

(19) CONTEXT: Which fruit here can you sell me?

(a) \#kaw plej ka hi hu süt poh h:o $\eta^{m}$ ni mĭn

(b) kaw plej $k a$ hi sit poh $h: \eta^{m} n i$ min hu $1 \mathrm{SG}$ sell to $2 \mathrm{SG}$ little CLF papaya this EMPH ROOT 'I can only sell you this papaya.'

Other tests for identificational focus include incompatibility with the universal quantifier and existentials like 'something' (É. Kiss 1998). However, object shift is felicitous with $p$. ih 'every' (20) and $w h$-indefinites (21). Note that we have yet to find appropriate counterparts for other tests such as 'also' and 'even' in Eastern Cham. 
(20) CONTEXT: Which fruits do you want me to buy at the market?

kaw băy hu pih poh j:aw hi plej

$1 \mathrm{SG}$ eat ROOT every CLF fruit $2 \mathrm{SG}$ buy

A: 'I can eat everything you buy.'

(21) CONTEXT: Can you eat anything?

kaw băg hu ket

$1 \mathrm{SG}$ eat ROOT what

'I can eat something.'

Instead, Eastern Cham object shift targets discourse-new information. In particular, it only targets alternative sets which are unique to the immediate Question Under Discussion (Roberts 1998). Reconsider (18') below: object shift is felicitous, because the alternative set of foods is unique to the question.

(18') CONTEXT: In the morning, what can you eat? [Speaking generally]

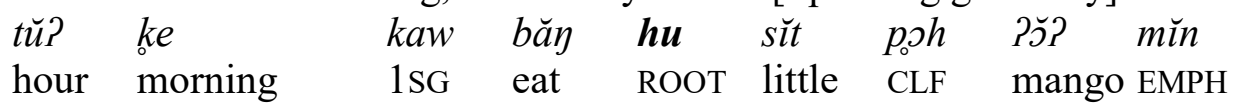

A: 'In the morning, I can only eat mango.'

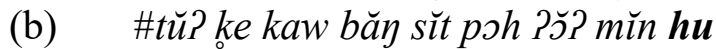

However, in (19'), which fruit is a D-linked question, and the fruits are visible, so the alternative set of fruits is already in the shared context prior to the question. Accordingly, object shift is infelicitous. We claim, thus, that Eastern Cham object shift represents true new information focus.

(19') ConTEXT: Which fruit here can you sell me? [fruits are visible]

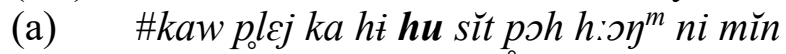

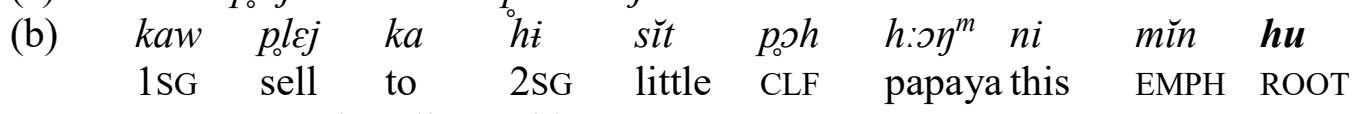

A: 'I can only sell you this papaya.'

It is worth mentioning here that 'object shift' is not limited to direct objects. Any focussed material in the predicate can be shifted, such as indirect objects (22) and locative adjuncts (23).

(22) CONTEXT: Who can you give a banana to?

kaw plej pthej hu ka çah ray năn ${ }_{\text {FOC }}$ mi:

$1 \mathrm{SG}$ give banana ROOT to only person that EMPH

A: 'I can only sell bananas to that person ${ }_{\text {Foc.' }}$

(23) CONTEXT: Where can I put beer?

hi $\quad c \breve{\varepsilon}$ ? bị:a $\quad \boldsymbol{h u}$ sĭt pă? l:am khin min

2SG put beer(VN) ROOT little in inside kitchen EMPH

'You can only put beer in the kitchen.'

In the mixed-headed approach, a natural analysis of object shift would involve right-dislocation of foci, perhaps to a phase edge (cf. López 2009 on Romance clitic right-dislocation). Such an analysis is given in (24a). Under the predicate-raising approach, object shift involves focus movement to a FocP projected below the Modal/AspectP, then remnant movement of the vP as above (24b). Note that Simpson (2001) calls the ModalP "DeP" to associate it specifically with Thai $d a i$ and its areal cognates. Additionally, he treats predicate-raising as movement to an intermediate YP below TP. Here, instead, we treat predicate-raising as movement to the specifier 
of the Modal/AspectP in order to account for the data given in Section 4 with multiple clausefinal particles. Third, we assume that external arguments are generated low in vP, unlike Simpson, who treats them as selected for by the clause-final particle itself.

(24a) Mixed-headed derivation of object shift

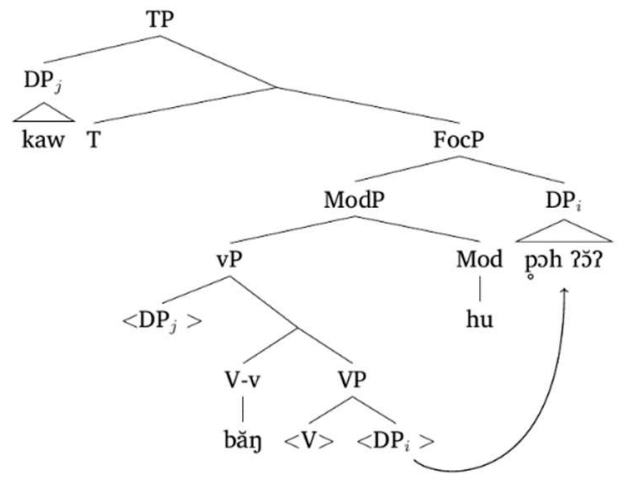

(b) Predicate-raising derivation of obj. shift

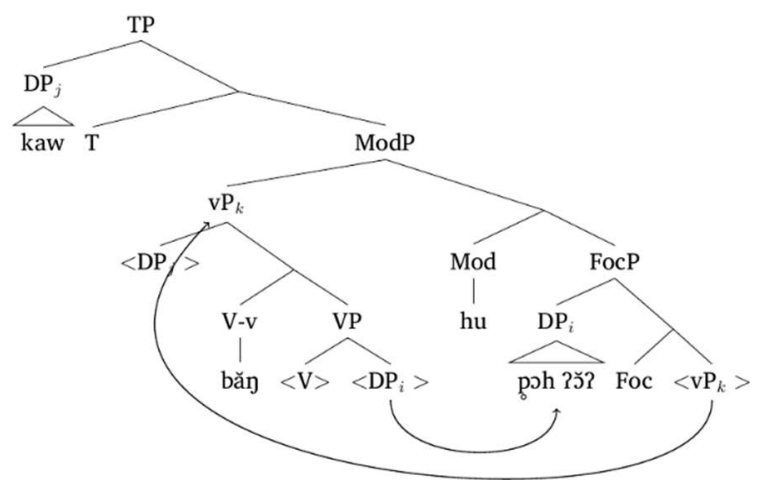

The mixed-headed approach in (24a) generally accords with focus movement cross-linguistically (especially Romance clitic disclocation). The projection of a FocP between vP and the ModalP in (24b) seems to be more unusual, as focus movement generally targets phase boundaries. However, the evidence in Section 4 will strongly favor this analysis.

4. Multiple clause-final particles and object shift. Something that has received little attention in the clause-final particle literature is the interaction between multiple cooccurring clause-final particles. As shown in Section 2, it is possible for certain of these particles to cooccur, especially $h u$ 'root modal' and $v \breve{t}$ ? 'iterative'. When these two clause-final particles cooccur, there are six possible permutations with the object, shown in (25). When the object is non-focussed (25a-b) are equally felicitous. When the object is focussed, $(25 \mathrm{c}-\mathrm{d})$ are equally felicitous. The final two orders (25e-f) are ungrammatical.

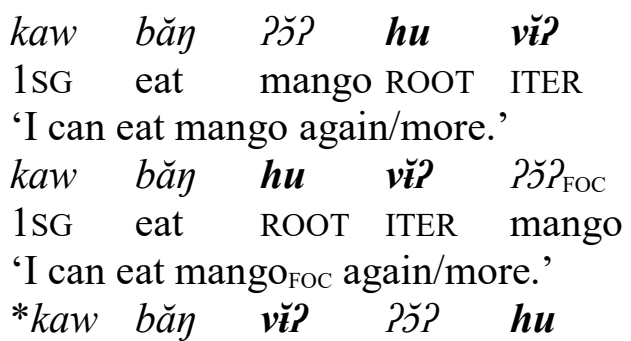

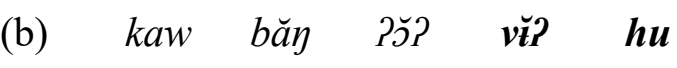

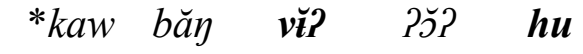

\begin{tabular}{|c|c|c|c|c|}
\hline (d) & kaw & $b \breve{a r y}$ & $h u$ & $P \breve{\partial} 2_{\mathrm{FOC}}$ \\
\hline (f) & *kaw & băn & $\nu \breve{t ?}$ & $h u$ \\
\hline
\end{tabular}

This paradigm can be replicated with other pairs of clause-final particles, like $h u$ 'root modal' and $\mathrm{min} / \mathrm{mi}$ : 'emphatic', and other focussed material in the predicate. (26) gives the same paradigm with $h u$ and $m i$ : and the indirect object. Note that 'only that old man' is a secondoccurrence focus in $(26 \mathrm{c}-\mathrm{d})$. Also note that scope is an outstanding issue in $(26 \mathrm{a}-\mathrm{d})$ : $m i$ : 'emphatic' seems to associate with 'only' in the subject, but it is unclear how the subject outscopes it. More research is needed to ascertain the relation between the emphatic and focus.

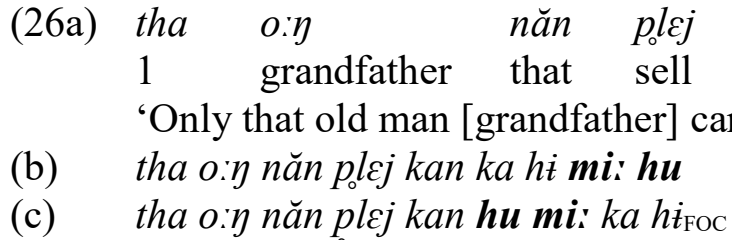
kan ka hi hu mi:
1 grandfather that sell fish to $2 \mathrm{SG}$ ROOT EMPH
(e) * tha o:y năn plej kan mi: ka hi hu
(d) tha o:y năn plej kan hu ka hi $\dot{\mathrm{FOC}}_{\mathrm{Fi}} \boldsymbol{m i}$
(f) *tha o:y năn plej kan mi: hu ka hì 
This data presents significant problems for the mixed-headed approach. Given the syntactic scope laid out in Section 2 and the right-dislocation analysis in Section 3, the mixed-headed approach predicts that the (e-f) examples above should be the grammatical ones (27). The (a-d) permutations could be achieved through additional movement. However, it is unclear how the (e-f) examples would be blocked, making this analyis overgenerative.

(27) Mixed-headed derivation for *(26f)

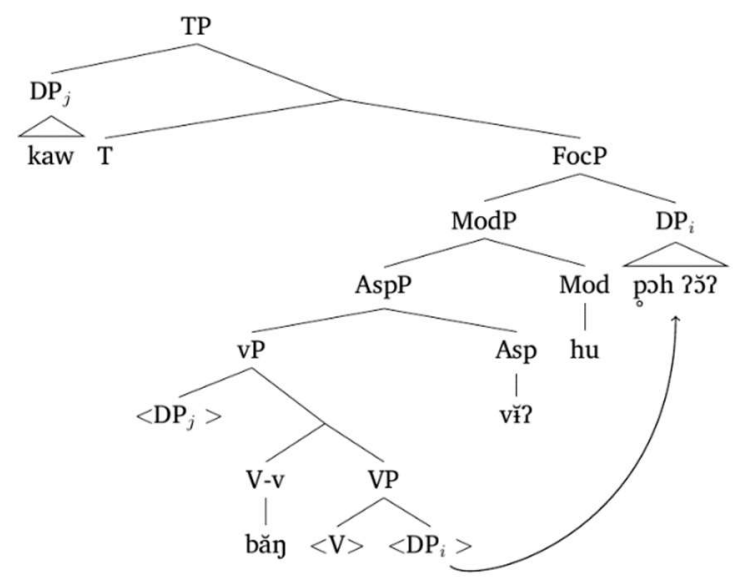

By contrast, the predicate-raising approach can easily accommodate for this paradigm. The (a) order results from raising the vP through Spec-AspectP to Spec-ModP (28a). The (b) order results from the roll-up style of movement described at the end of Section 2 (28b). Neither of these orders require any recourse to focus, as the object is non-focussed.

(28a) Predicate-raising analysis of (26a)

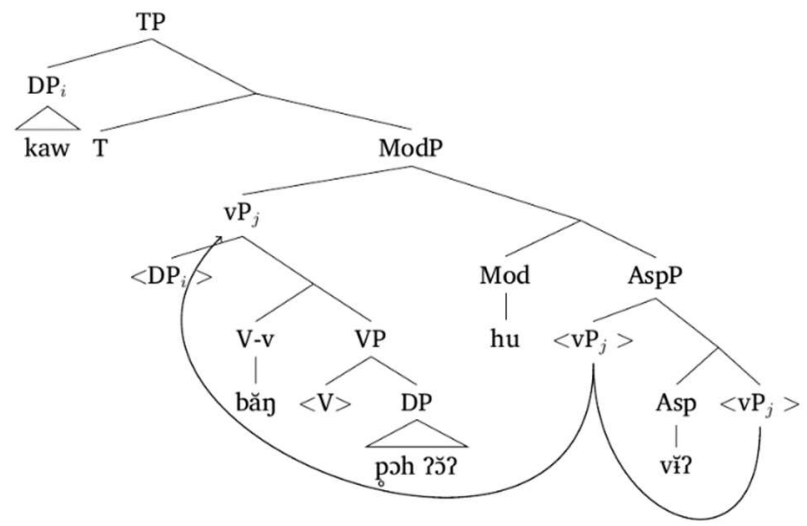

(b) Predicate-raising analysis of (26b)

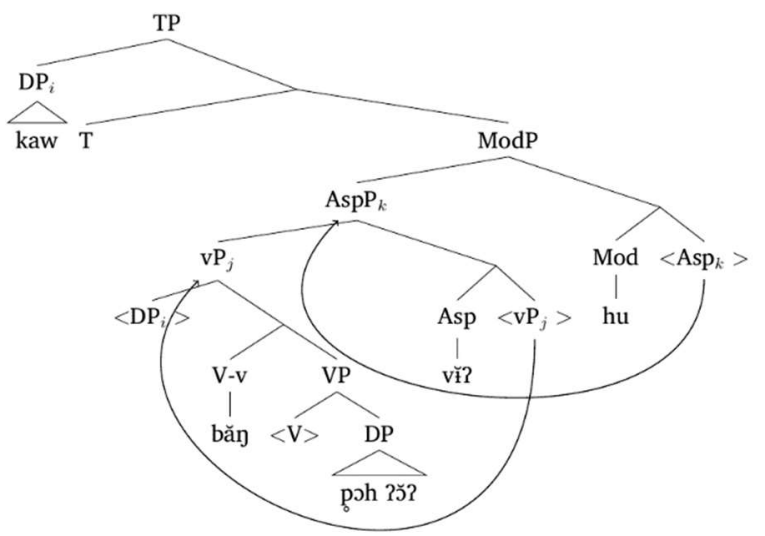

When the object is under focus, the (c) order results from focus movement to a FocP projected above vP (28c), and the (d) order obtains when the object moves through the lower FocP to a FocP projected above AspectP (28d). 
(28c) Predicate-raising analysis of (26c)

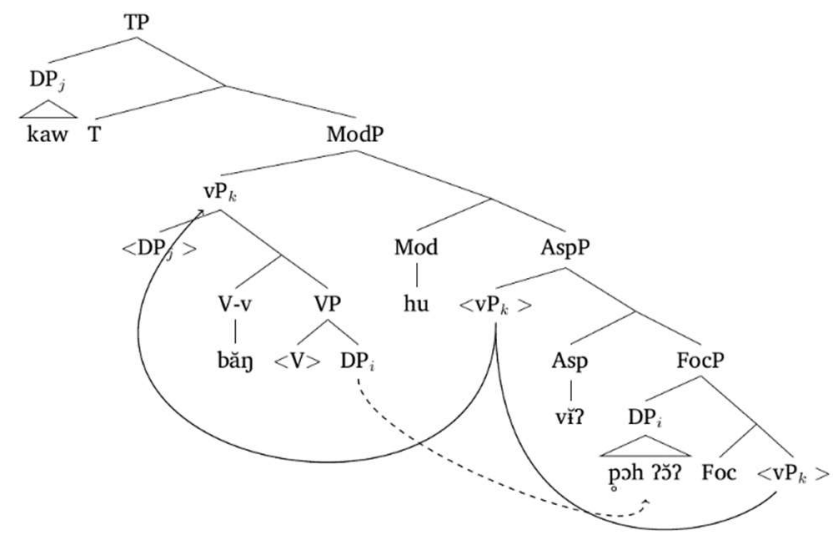

(b) Predicate-raising analysis of (26d)

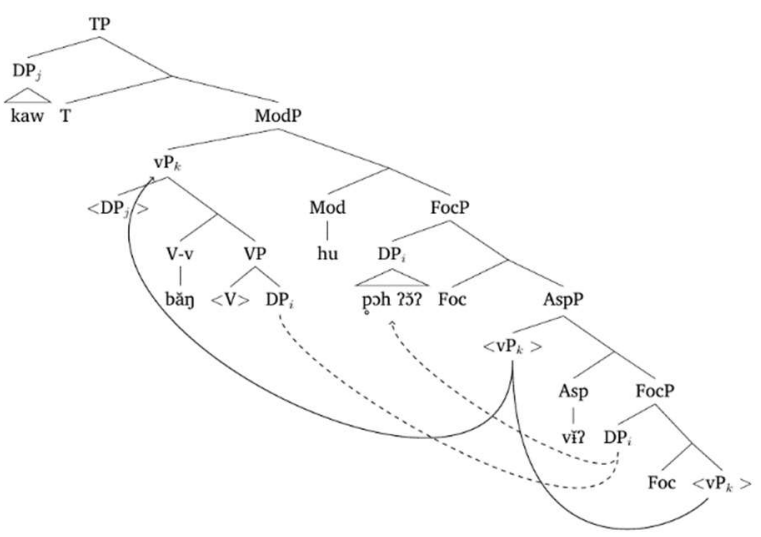

Finally, the ungrammatical (e-f) orders are blocked for at least two potential reasons. First, $\mathrm{Mod}^{\mathrm{O}}$ and $\mathrm{Asp}^{\mathrm{O}}$ could have a feature such as [-Focus] or [+Given] that force their specifiers to contain non-focussed information. This analysis would require information structure features to percolate upwards through phrases (cf. Erteschik-Shir 2006). For the (e-f) orders to obtain, rollup movement of AspectP to Spec-ModalP must occur, but the AspectP necessarily contains a FocusP. In other words, it must contain focussed material, violating this featural restriction.

Second, these derivations could involve illicit movement. If predicate-raising and focus movement are both to be considered $\bar{A}$-movement, this would violate a known constraint on remnant movement. According to Takano (2000) and others, there is a constraint that remnant movement of an XP and the movement out of that XP cannot be of the same type (e.g. * ${ }^{*}$ movement $/ \overline{\mathrm{A}}$-movement). The derivation in (28f) would violate this constraint.

(28f) Crashed derivation for (26f)

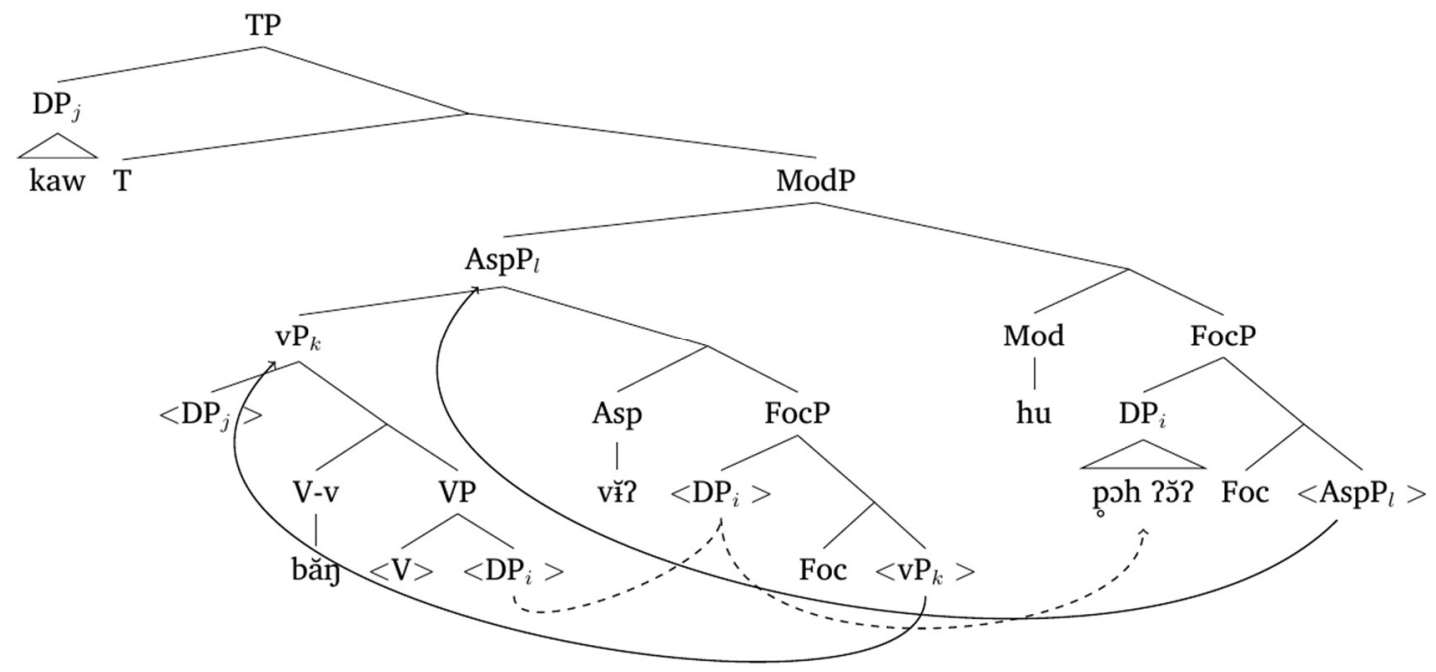

Intuitively, this seems to be the right prediction. Object shift in Eastern Cham appears to a way to vacate focussed material out of the predicate before predicate-raising. The (e-f) orders both would involve putting the focussed material back into the phrase (AspectP) that undergoes raising, negating the intent of the previous movement operation. 
5. Conclusion. Overall, only a predicate-raising analysis in the vein of Simpson (2001) can account for the Eastern Cham clause-final particle and object shift data. This preserves a rightbranching structure in a language that is otherwise largely right-branching (pace Kayne 1994).

Based on data from multiple cooccurring clause-final particles, we propose slight modifications to Simpson (2001)'s analysis. Clause-final particles trigger predicate-raising to their own specifiers (unless one is willing to posit multiple intermediate YP's in between each Modal/AspectP). External arguments are generated low in vP, not by the clause-final particle itself. Third, we propose that there is a broader set of clause-final particles, occupying Modal/AspectP's.

It should be mentioned that this analysis of focus movement could be problematic for theories of information structure. Focus movement is generally treated as (a) movement either to phase boundaries (López 2009), (b) evacuative movement to avoid topic marking (Samek-Lodovici 2015), or (c) movement to a separate prosodic phrase due to prosodic constraints (e.g.

Zubizarreta 1998). However, the focus movement in (28d) does not obviously meet any of these conditions. For (a), one would have to posit a phase boundary in between each modal or aspect marker, which is undesirable. For (b), the focus has already evacuated topic marking; why should it move again to the higher FocP? And for (c), the focus is not moved to a phrase edge; it is instead sandwiched between a modal and an aspect marker, with no attendant pause. More research is needed to ascertain the motivation for this focus movement.

A number of additional questions remain. First, how would this analysis derive focussed subjects? On this front, it should be noted that Eastern Cham is a topic-prominent language. Focussed phrases generally must be clefted in order to be subjects, and unmarked subjects are usually given. Second, what are the properties of sentence-final, discourse-level particles, like the polar question marker hlej? After Erlewine (2017)'s work on Mandarin sentence-final particles, one may suspect that they would be less amenable to a right-branching structure. Another question worth addressing is what are the interpretive differences between (26a-b) and $(26 \mathrm{c}-\mathrm{d})$, respectively? The contextual control given in this paper is not fine-grained enough to detect a meaning difference between these pairs. Last, how do these facts compare to the contact language, Vietnamese? It is possible that this pattern is largely replicable with clause-final particles like nữa 'more', được 'root modal', and chỉ... thôi 'only'.

As a final note, we will propose a general information structure for clause-final particles on analogy with Rizzi (1997)'s account of CP-level FocP's. Rizzi describes left-peripheral FocP's as partitioning the sentence into a focus (specifier) and a presupposition (complement), schematized in (29a). Clause-final particles perform a similar task under this analysis: they partition a predicate into a focus (complement) and a presupposition (specifier).

(29a) Generalized FocP, after Rizzi (1997)

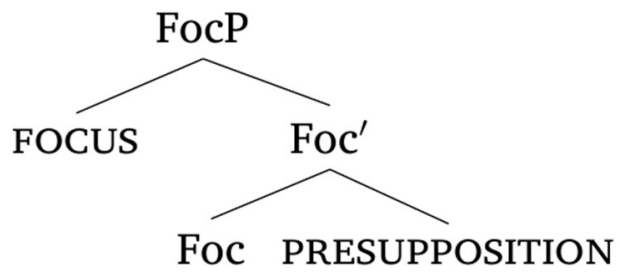

(b) Generalized clause-final particle phrase

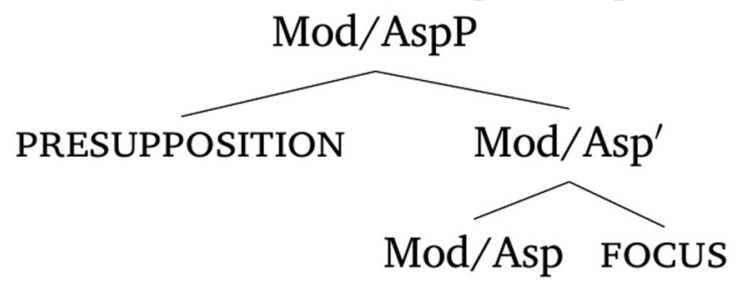

Both FocP and clause-final particles have additional, seemingly unrelated semantics. Leftperipheral FocP's also coincide with $w h$-movement. Despite the relation between $w h$-phrases and 
foci in standard alternative semantics, Rizzi and others consider this a coincidental overlap. Clause-final particles additionally add the semantics of modality or aspect, which could also be seen as a coincidental overlap brought about by a structural unity.

The two focus phrases also share optionality. If there is no focus movement, according to Rizzi, no FocP is projected. Likewise, if there is no focussed material in the predicate, no FocP is projected below clause-final particles. Clause-final particles, thus, may be the predicate-level analog to Rizzi’s left-peripheral FocP.

\section{References}

Baclawski Jr., Kenneth. 2016. Triglossia in Eastern Cham. Paper presented at New Ways of Analyzing Variation Asia-Pacific 4 (NWAV-AP4). Chiayi, Taiwan. National Chung Cheng University.

Enfield, N.J. 2003. Linguistic epidemiology: Semantics and grammar of language contact in mainland Southeast Asia. Routledge Curzon. http://dx.doi.org/10.4324/9780203605196

Erlewine, Michael Yoshitaka. 2017. Low sentence-final particles in Mandarin Chinese and the Final-over-Final Constraint. Journal of East Asian Linguistics 26. 37-75. http://dx.doi.org/10.1007/s10831-016-9150-9

Erteschik-Shir, Nomi. 2006. On the architecture of topic and focus. In Valéria Molnár \& Susanne Winkler (eds.), The architecture of focus. 33-58. Mouton de Gruyter. http://dx.doi.org/10.1515/9783110922011

Horváth, Júlia. 2010. Discourse features, syntactic displacement, and the status of contrast. Lingua 120. 1346-1369. http://dx.doi.org/10.1016/j.lingua.2008.07.011

Kayne, Richard. 1994. The Antisymmetry of Syntax. MIT Press.

Kiss, Katalin É. 1998. Identificational focus versus informational focus. Language 74. 245-273. http://dx.doi.org/10.1353/lan.1998.0211

Krifka, Manfred. 2006. Association with focus phrases. In Valéria Molnár \& Susanne Winkler (eds.), The architecture of focus. 105-136. Mouton de Gruyter. http://dx.doi.org/10.1515/9783110922011

López, Luis. 2009. A derivational syntax for information structure. Oxford University Press. http://dx.doi.org/10.1093/acprof:oso/9780199557400.001.0001

Martins, Ana Maria. 1994. Enclisis, VP-deletion and the nature of Sigma. Probus 6. 173-206. http://dx.doi.org/10.1515/prbs.1994.6.2-3.173

Moussay, Fr. Gérard. 2006. Grammaire de la langue cam. Les Indes Savantes. Mission Étrangères de Paris. Paris.

Rizzi, Luigi. 1997. The fine structure of the left periphery. In Liliane Haegeman (ed.), Elements of grammar: A handbook of generative syntax. 281-327. Kluwer. http://dx.doi.org/10.1007/978-94-011-5420-8 7

Roberts, Craige. 1998. Information structure in discourse: Towards an integrated formal theory of pragmatics. Semantics \& Pragmatics 5. 1-69. http://dx.doi.org/10.3765/sp.5.6

Samek-Lodovici, Vieri. 2015. The interaction of focus, givenness, and prosody: A study of Italian clause structure. Oxford University Press. http://dx.doi.org/10.1093/acprof:oso/9780198737926.001.0001

Simpson, Andrew. 2001. Focus, presupposition and light predicate raising in East and Southeast Asia. Journal of East Asian Linguistics 10. 89-128. 
Simpson, Andrew. 2005. Classifiers and DP structure in Southeast Asia. In Guglielmo Cinque \& Richard Kayne (eds.), The Oxford handbook of comparative syntax. 806-939. Oxford University Press. http://dx.doi.org/10.1093/oxfordhb/9780195136517.013.0018

Sneddon, James, Alexander Adelaar, Dwi Noverini Djenar \& Michael C. Ewing. 2012. Indonesian reference grammar, 2nd edition. Routledge.

Takano, Yuji. 2000. Illicit remnant movement: An argument for feature-driven movement. Linguistic Inquiry 31(1). 141-156. http://dx.doi.org/10.1162/002438900554325

Thompson, Laurence. 1987. A Vietnamese reference grammar. University of Hawai'i Press. Originally published in 1965.

Visonyanggoon, Saisunee. 2000. Parallelism between noun phrases and clauses in Thai. East Lansing, Michigan. Michigan State University dissertation.

Zubizarreta, Maria Luisa. 1998. Prosody, focus, and word order. MIT Press. 